\title{
Symbolic Conscious Experience
}

\author{
Venkata Rayudu Posina*
}

\section{Abstract}

Inspired by the eminently successful physical theories and informed by commonplace experiences such as seeing a cat upon looking at a cat, conscious experience is thought of as a measurement or photocopy of given stimulus. Conscious experience, unlike a photocopy, is symbolic-like language - in that the relation between conscious experience and physical stimulus is analogous to that of the word "cat" and its meaning, i.e., arbitrary and yet systematic. We present arguments against the photocopy model and arguments for a symbolic conception of conscious experience. Learning and the corresponding plasticity of the brain make a strong case for the symbolic conception of conscious experience, while many extra-ordinary conscious experiences argue against the formalisation of consciousness as a measuring device. The notions of place-value notation and grammar, which organise quantitative measurements and conscious experiences in the medium of numbers and language, respectively, are suggested as model systems for putting together a comprehensive theory of conscious experience.

Keywords: Brain, Language, Measurement, Plasticity, Reality, Syntax

\footnotetext{
* Consciousness Studies Programme, National Institute of Advanced Studies, Indian Institute of Science Campus, Bengaluru, Karnataka, India; posinavrayudu@gmail.com
} 


\section{Introduction}

In physics we have quantum theory telling us all that "we can say about nature" (Zeilinger, 2000). In biology we have the theory of evolution without which, in the words of Dobzhansky, "nothing in biology makes sense" (Dobzhansky, 1973). In modern science, sadly, there is nothing that qualifies as a comprehensive theory of conscious experience, with consciousness remaining a mystery (Albright et al., 2000). This state-of-affairs is a result of neuroscientists subscribing to photometer metaphor or, more broadly, measurement-device conception of perception (Gilchrist, 1994; Mausfeld, 2002). Cognitive neuroscientists, fascinated by the success of physics, readily adopt physical paradigms in thinking about conscious experience. A careful examination of the evolution of scientific models of facets of conscious experience such as memory, however, brings into sharp focus the possibility of a clearer understanding of conscious experience without necessarily having to imitate successful physical models. Early models of memory were physical in the sense that memory was modeled as a thing put in some place. Recollection, in this memory model, required specifying the location of the stored memory. Conventional computer memory is an implementation of this memory model: we have to specify the address of the memory store in order to retrieve the contents stored at that address. Abstracting from the everyday experience of using a part of memory (i.e. hint) to recollect the rest of memory, science found a better alternative of using content [itself] as address, leading to the development of content-addressable memories of neural networks (Hopfield, 1982).

The lessons of the history, briefly noted above, raise the possibility that the measurement-device conception of conscious experience that dictates much of the current cognitive neuroscience research is more of a reflection of the old habit of thinking in physical terminology and less of a description of conscious experience. This photocopy model of conscious experience is reminiscent of the out moded theory of art as "imitation of reality" (Sontag, 1966). According to measurement-device conception, conscious experience is a measurement, say 10 , of a stimulus. But ' 10 ' in and of itself is not very telling in the sense that the symbol string 10 
could mean, for example, ten (in base ten place-value notation) or two (in base two notation). Simply put, a reading of measurement is a [place-value] notation in addition to being a quantity. Conscious experience, to the extent it is telling, is also a notation that is not given in any stimulus or [its] measurement. Conscious experience, like the notion of notation, is arbitrary (an act of creation) and yet systematic (Kandel, Schwartz \& Jessell, 2000, p. 493). While the notion of measurement captures the systematic aspect, a symbolic conception of conscious experience is required to capture the notational (arbitrary and systematic) aspect of experience. Our faith, fostered in part by the [partial] congruence of physical and perceptual terminology (e.g. 'round ball' is perceived as 'round ball'), in the doctrine asserting that perception is a photocopy (albeit a noisy, degraded, or low-resolution one) of the physical reality seems to prevent us from recognising the symbolic quintessence of conscious experience.

In the present note, we motivate the needed paradigm shift (from photocopy to symbol) in our conceptualisation of conscious experience. We begin with descriptions of conscious experiences that do not fit neatly within the photocopy framework and present detailed arguments in favor of the symbolic conception of conscious experience. Our symbolic conception of conscious experience is comparable to the interface theory of perception (Hoffman, Singh \& Prakash, 2015). The symbolic conception, in addition to the stimulus-percept semantics, is the needed syntax for putting together a comprehensive theory of conscious experience.

\section{I of It}

In Principles of Neural Science, in the famous Madeleine passage, which opens the study of perception, Marcel Proust identifies with his perceptual experience: "this essence [the taste of Madeleine] was not merely inside me, it was me" (Kandel, Schwartz \& Jessell, 2000, p. 408). In the practice of neuroscience, however, there is no mistaking me for my perceptual experience; the distinction between perceiver and perceived defines perception. Proust's liberal interpretation of the constitution of I provides impetus for a searching examination of this seemingly self-evident axiom. 
I identify with my body: that bony, skinny, bloody body, which is conceptualised as a container into which are collected all of my perceptual experiences, even though my perceptual experience of the body, as seen from the perspective of perception, is a percept just like innumerable other percepts such as the black cursor blinking in front of me, the air-conditioner humming above, and the keys felt under my fingertips. A part of my perception (body) is ' $\mathrm{I}$ ', while the rest (tables, chairs, computers...) is relegated to the distant realm of 'it'. The conceptual shallowness of this convention can be gauged by visualising a 'form of intuition', whose inhabitants identify themselves with their pinkies and treat the rest of their bodies as some kind of extraneous stuff that happens to be. This is not to deny the possibility of my body percept being unique in some respect amongst all of my perceptual experiences somewhat analogous to the way color percept, for instance, is distinguished from percepts of (say) shape and size by virtue of being not verifiable in modalities other than visual. In the absence of a distinguishing criterion, singling out my body to identify with myself, however, does sound scriptural. An illustration from middle-school mathematics may further clarify. Number one is distinct from rest of the numbers not because it would be nice to say number one is special, but by virtue of a property unique to number one (with respect to multiplication): $1 \times n=n$, where $n$ is any number. Within the domain of perceptual discourse, the distance separating the perceptual experience of my body from the tastes I taste, the thoughts I think, the voices I hear, the faces I see, etc., appears to be in search of a metric. The fluidity of these notions - the perceiving I and the perceived it - is what Proust is inviting us to ponder when he prophetically pronounces that the taste of Madeleine is not in him, but that that is him.

The identification of perceiver with perceived is not simply an argument [to be] made plausible by reason or rhetoric; it is perception-pure and proper-though not necessarily ordinary or commonplace. A clear description of one such percept can be found in the very first paragraph of Proust's magnum opus: "I myself seemed actually to have become the subject of my book: a church, a quartet, the rivalry between François I and Charles V" (Proust, 1922 , p. 2). In addition to finding oneself in the other, the other is, at times, included in oneself via, as highlighted by Marx, "a 
prolongation of body" (Scarry, 1994, p. 85). Cultivating compassion is another instance of ' $\mathrm{I}$ ' expanding to encompass, in Darwin's words, "all sentient beings" (Ekman, 2010). Though modern students of consciousness, abstracting from ordinary experience, treat the subject who perceives and the object that is perceived as given, and explain perceptual experiences in terms of the structure and properties of the perceiving subject and those of the perceived object, conscious experiences wherein the very percept is the identity of perceiving subject with perceived object clearly indicate that the subject-object divide that is hitherto treated as given is also a perceptual construct, and as such is in need of explanation as much as the percept of, say, color black. The following analogy illustrates the point. Chemists, in studying reaction rates, treat elements as given, but that did not prevent Fred Hoyle, for one, from theorising about the origin of those very elements. Put differently, seeking the experiential resolution of conscious experience into being and experience of the being, by the being, and for the being is in the character of science.

In addition to the standard fare of shape, motion, and color perception that looks as though it is explained by the reality of punctate photons impinging on photoreceptors (Henry, 2005), there is, as alluded to already, a whole enchilada of experiences, the diversity of which is barely documented in neuroscience, but is intimately familiar to students participating in aesthetic and spiritual practices. The presence of experiences not exhibiting the usual Edgar Rubin faces of actor vs. audience, for example, of reducing oneself to a pure spectator mode of being ( $d$ 'Amboise, 2006), is not immediately felt in the modus operandi of neuroscience. A not so esoteric feeling of 'losing oneself' that some of us might have experienced while listening to music is one such experience from the ethereal expanse of experience beyond the Looking-Glass (of Lewis Carroll), which has been the subject of neuro-scientific investigations (Goldberg, Harel \& Malach, 2006). We hope many more of these extra-ordinary experiences are brought within the curriculum of consciousness before they become extinct: experientially extinct! Not too long ago metaphysical poets, as T. S. Eliot noted, felt their thoughts. With consciousness whittled down to a photocopier, 'feeling thought' is foreign - so foreign that we cannot comprehend what it means to 
have "a direct sensuous apprehension of thought, or a recreation of thought into feeling" (Eliot, 1975, p. 63). And, with feelings reduced to muscular reflexes, hardly anyone can experience the ecstasy of 'disappearing into the appearance' of one's love that was so palpable for Rumi and his ilk (Graham, 1987). Not very much unlike an anthropologist struggling to understand a lifestyle different from her or his own, we have a responsibility to refrain from castigating these distant conscious experiences for being part of humanities and embrace them in a pensive mood for systematic study. Furthermore, recognising the debt that molecular biology (the revolution we are living) owes to our appreciation of the biological diversity is a stimulus strong enough to look at the entire range of conscious experiences unfiltered by our contemporary sensibilities wrought by factors extraneous to the scientific pursuit of consciousness.

Beyond the jurisdiction of 'being determines consciousness', besides the everyday experiences that appear to obey the causal stimulus $\rightarrow$ percept framework, there are experiences violating the laws of narrative realism - reified linearity of the narrative - of "the run run of story" (Graham, 1990). In providing a comprehensive account of consciousness-redefined collectively by the varieties of experiences-the mainstream and the marginalised-we need to abstain from deploying many of the intuitions that we inherited. Borrowing a phrase from Gertrude Stein, to make our point, "there is no there there," but for conscious experience. Conscious experience, not unlike the creative poet that Shakespeare spoke of (in 'A Midsummer Night's Dream'), endows [the acutely felt] existence with "a local habitation and a name", spelled as reality. There is no room for reality, except as a construct like color or confabulation, in the proper study of perception. Reality, as it figures in conscious experience, is a poetic artifact of prosaic articulation. Being students of perception, perceptive of illusions competing with reality for the status of real, aren't we primed sufficiently to subscribe to Proustian I? In spite of the existence with its imposing 'is' and I with its august 'am' insisting on being, we cannot be conservative believers in contemplating conscious experience; we need to be nastik: unbelieve in being. 


\section{Symbolic Conscious Experience}

Perceptual experience is not a [mere] measure of the reality outthere, which resonates with mathematician's view of mathematics. Notwithstanding the "unreasonable effectiveness of mathematics" (Wigner, 1960), mathematicians do not treat numbers merely as a model of quantities - heights and weights - out there in the world. Had mathematicians done so, neither would they have conceived the notion of prime number (a notion inherent in representing numbers but not in represented heights or weights), nor would they have constructed the place-value notation, which is just thata notation-not an emergent property of any measured quantity. But for the poetic place-value notation, mankind would still be adding numbers with fingers and toes. In algebra we notice that a representation (un-spatial symbols) can be an effective instrument for manipulating the represented (spatial surfaces and solids) without necessarily having to mirror that which is represented. More explicitly, the pictorial resemblance between algebraic symbols and the signified geometric objects is completely irrelevant in the practice of algebra. In mathematics, as David Hilbert makes it abundantly clear, "one must be able to say at all times - instead of points, lines, and planes - tables, chairs, and beer mugs". Analogous symbolic nature of the relation between perception and physical stimulus is indicated, to note a neuroscientific study, by the neurophysiological finding that arbitrary static shapes symbolising motion directions activate, upon learning the associated meanings, neurons coding motion perception (Schlack \& Albright, 2007). The symbolic relation between perceptual experience and physical reality encourages the study of appearance [with reality bracketed], along the lines of algebra. Following in the footsteps of the mathematical practice of treating imaginary number as real as real number in calculations, thoughts are considered as "real" as things and are "equivalent" in the scientific (i.e. methodical) program of conceptualising conscious experience. After all, in conscious experience the two domains of discoursethings and thoughts - are constantly translated into one another as we make things we think of and as we think about things that are.

The [undefined] primordial conscious experience of early life differentiates, via a thousand cuts such as the spectator-spectacle 
subdivision and the schism between spatial intuition and symbolic reason, into our everyday experience of cars speeding, people smiling, and walls standing still all within the confines of yet another construct called reality. The diversification of conscious experience is reminiscent of and possibly a [vast] generalisation of the more thoroughly studied figure-ground segmentation of visual images. When I see these black contours against white background, for example, I not only see the colors and the shapes, but also experience the subjectivity of seeing and the objectivity of the seen, to name a couple of species of experience. The study of conscious experience, however, has been, for methodological convenience, focusing on the changes in perception and associated neuronal activities as the learned neuroscientist varies physical stimuli. The causal questions to which this experimental paradigm readily lends itself are definitely important, but equally important are questions of fit: the question of how features like color and shape fit together or of how modalities like vision and touch relate to one another or of how perception, conception, emotion, intuition, desire, intention, action, etc. all cohere into that which we call conscious experience (Roskies, 1999). Unlike the fit between organism and environment, which guided the development of the theory of evolution, the notion of 'fit' appropriate for the domain of consciousness discourse is that of 'coherence' of languages-of combining signification-free alphabet into meaningful words, and of combining truth-value free words into truthful statements (cf. it makes no sense to ask: is "cat" true?, but makes perfect sense to ask whether a statement: 'cat is on the mat' is true). Development of a comprehensive theory of conscious experience can draw on the experience of designing languages (beginning with "arbitrary" alphabet and building all the way to linear narratives and nonlinear verse via rules of composition) and of mathematical practices (founded in un-defined terms and well-defined rules of substituting symbols). Treating mathematics as a specialisation of ordinary language, the project of comprehending conscious experience can be concisely stated as a generalisation of symbolic language, analogous to the algebraic generalisation of arithmetic. The understanding of mathematical structures in terms of presentation-representation (Lawvere, 2004) in particular, and of languages in terms of syntax-semantics in general can be adopted 
as a thinking device in the conceptualisation of conscious experience.

Conscious experience, like the symbols constituting this text, readily lends itself to material interpretations. Comprehending conscious experience, just as is the case with symbolic language, calls for more than a mastery of the material things signified by conscious experience i.e., creation and codification of the syntax for conscious experience. Though we begin our education with associational semantics as in associating the sound 'cat' with the thing 'cat' out-there, we "unlearn" the thing meaning of cat and learn that the [word] cat is not made up of [real] tail or whiskers but is made up of made-up alphabets. In comparing conscious experience to symbolic language, we see the need for the development of syntax for conscious experience in addition to compiling the dictionary of physical stimuli-conscious percepts associational semantics. Symbolic conception of conscious experience argues for according conscious experience, for the purposes of a coherent description of conscious experience, an existence in-and-of-itself separate from its material meanings analogous to the way we accord words (in language) an existence apart from their meaning. The symbolic conception of conscious experience, with symbol as both itself and that which it signifies, can be understood as a generalisation of measurement-device conception of conscious experience. Within the framework of symbolic conscious experience, without denying the fact that a physical stimulus elicits a perceptual experience, stimulus is a particular interpretation of conscious experience. This paradigm is modeled after theoretical physics, wherein, say, people enter theory, but only as physical notions such as heights and weights and not as they are with all their conflicting feelings and desires.

\section{Conclusion}

Perception, for the purpose of understanding conscious perceptual experience, is original. Acknowledging the primacy of perception is akin to treating line as elemental (with point treated as a line of zero length, as a derived entity, as opposed to treating point as the foundational element), with perceiver and perceived relegated to the status of endpoints of the line. More importantly, when we treat 
consciousness as a measuring device mirroring reality, we are limiting our understanding of conscious experience. Be that as it may, pretending that there really is something behind the veil of experience that looks and is somewhat like what I see is a habit that is so internalised, not to mention the potentially fatal consequences of acting otherwise, that it is not easy to renounce the notion of underlying reality, leave alone embrace the concept of emptiness and see "the groundlessness of things" (Priest, 2009). Accommodating the bewildering diversity of species of consciousness without invoking underlying reality and without discounting the ambient aboutness intrinsic to experience is, it must be admitted, daunting, if at all feasible. The project of perception-without-perceiver [perceived], as intimidating as it is, appears approachable in light of Darwin's theory of biology: design-without-designer!

\section{References}

Albright, T. D., Jessell, T. M., Kandel, E. R. and Posner, M. I. (2000). Neural science: A century of progress and the mysteries that remain. Neuron, 25, S1-S55.

d'Amboise, J. (2006). The mind in dance. Daedalus, 135, 76-77.

Dobzhansky, T. (1973). Nothing in biology makes sense except in the light of evolution. The American Biology Teacher, 35, 125-129.

Ekman, P. (2010). Darwin's compassionate view of human nature. The Journal of the American Medical Association, 303, 557-558.

Eliot, T. S. (1975). The metaphysical poets. In F. Kermode (Ed.), Selected Prose of T. S. Eliot. New York, NY: Harcourt Inc.

Gilchrist, A.L. (1994). Theories of lightness perception. In A.L. Gilchrist (Ed.), Lightness, Brightness, and Transparency. Hillsdale, NJ: Lawrence Erlbaum.

Goldberg, I. I., Harel, M., \& Malach, M. (2006). When the brain loses its self: Prefrontal inactivation during sensorimotor processing. Neuron, 50, 329-339.

Graham, J. (1987). Orpheus and Eurydice. In The end of beauty. New Jersey, NJ: Ecco Press. 
Graham, J. (1990). Introduction. In J. Graham and D. Lehman (Eds.), The best American poetry 1990. New York, NY: Scribner Book Company.

Henry, R. C. (2005). The mental universe. Nature, 436, 29.

Hoffman, D. D., Singh, M., and Prakash, C. (2015). The interface theory of perception. Psychonomic Bulletin $\mathcal{E}$ Review, 22, 14801506.

Hopfield, J. J. (1982). Neuronal networks and physical systems with emergent collective computational abilities. Proceedings of the National Academy of Sciences USA79, 2554-2558.

Kandel, E. R., Schwartz, J. H., and Jessell, T. M. (2000). Principles of neural science (4th ed.). New York, NY: McGraw-Hill.

Lawvere, F. W. (2004). Functorial semantics of algebraic theories and some algebraic problems in the context of functorial semantics of algebraic theories. Reprints in Theory and Applications of Categories, 5, 1-121.

Mausfeld, R. (2002). The physicalistic trap in perception theory. In: D. Heyer and R. Mausfeld (Eds.), Perception and the physical World, Chichester, UK: Wiley.

Priest, G. (2009). The structure of emptiness. Philosophy East and West, 59, 467-480.

Proust, M. (1922). Swann's way. New York, NY: Henry Holt and Company.

Roskies, A. L. (1999). The binding problem. Neuron, 24, 7-9.

Scarry, E. (1994). Resisting representation. New York, NY: Oxford University Press.

Schlack, A. and Albright, T.D. (2007). Remembering visual motion: Neural correlates of associative plasticity and motion recall in cortical area MT. Neuron, 53, 881-890.

Sontag, S. (1966). Against interpretation. In S. Sontag (Ed.), Against interpretation and other essays, New York, NY: Farrar, Strauss \& Giroux.

Wigner, E. (1960). The unreasonable effectiveness of mathematics in the natural sciences. Communications in Pure and Applied Mathematics, 13, 1-14.

Zeilinger, A. (2000). The quantum centennial. Nature, 408, 639-641. 